\title{
LA TRADUCCIÓN COLABORATIVA ACTIVISTA CONTEMPORÁNEA EN CANADÁ Y EN BRASIL: COMUNIDADES DE TRADUCCIÓN 1.0 Y 2.0 EN EVOLUCIÓN
}

\author{
Raúl Ernesto Colón Rodríguez
}

\section{Introducción}

\begin{abstract}
La vida es pues, esencialmente, fruto de la diversidad de órganos, de interacciones, de pareceres diversos y cambiantes. Todo lo contrario de la exaltación de la permanencia de opiniones, pareceres, pertenencias o adscripciones. La esencia de la vida y su soporte son, al contrario, interacciones constantes entre agentes al borde del caos o instalados en la complejidad.

EDUARDO PUNSET. El viaje al poder de la mente
\end{abstract}

Vivimos tiempos de cambio, no sólo geopolítico, generacional, social, o de un nuevo milenio. Vivimos en una época de cambio de paradigmas y ello significa que en el mundo de las ciencias sociales tenemos que prestar mucho más atención a los descubrimientos que se hacen cada día, pues el ritmo de esos descubrimientos ha sido exponencial desde que las "certitudes ideológicas", que de manera global los frenaban, así como al respectivo reconocimiento y aplicación que debe seguirles, se vinieron abajo finalmente en $1991^{1}$, primero para reforzar uno de los polos del antiguo mundo bipolar, pero luego y cada día más, para dar paso a un mundo multipolar, que probablemente durante mucho tiempo seguirá en construcción ${ }^{2}$.

Si ese ha sido el telón de fondo geopolítico, el tecnológico es tan importante o más. Para el presente año 2015 se espera que hayamos alcanzado 8 zettabytes de información a

\footnotetext{
${ }^{1} 1991$ es una fecha es emblemática por ser la del derrumbe de la URSS, la desaparición del Pacto de Varsovia y el comienzo del mundo unipolar, es decir, el cambio geopolítico más importante de la contemporaneidad. Eric Hobsbawm en su célebre libro The Age of Extremes: A History of the World, 1914-1991 acuñó esta fecha como la del final del "corto siglo XX" (Hobsbawm, 1995).

${ }^{2}$ En ese sentido han sido de gran interés los seminarios celebrados en 2010 de la publicación francesa Monde Diplomatique, titulados: Géopolitique du monde multipolaire (Geopolítica del mundo multipolar). Entre ellos se destaca: Du monde bipolaire au monde multipolaire en passant par l'unipolaire (Del mundo bipolar al mundo multipolar, pasando por el unipolar). Ver: <http://www.cartografareilpresente.org/article521.html>, (Página consultada el 13 de enero de 2015).
} 
COLÓN RODRÍGUEZ - La traducción colaborativa activista contemporánea...

nivel global (Floridi, 2014, p. 13). Si tenemos en cuenta que durante toda la historia de la humanidad y hasta el surgimiento de las computadoras se habían acumulado tan sólo 12 exabytes de información y que luego — tan sólo entre 2006 y 2011 — se pasó de 180 a 1600 exabytes, es decir que en un espacio de tiempo mínimo, en comparación con todo el precedente, se superó la barrera del primer zettabyte (o lo que es lo mismo, el equivalente a 1000 exabytes). Luego de tal salto exponencial en nuestra capacidad de almacenamiento de los conocimientos, sin dudas seguiremos acumulando información y ganando en la rapidez de su procesamiento, esta vez a razón de uno o varios zettabytes por año, quién sabe si llegue a ser mucho más. Estos cambios de escala no pueden sino provocar, en las sociedades expuestas, cambios de dimensión de todo orden y con ellos el surgimiento de replanteamientos de todo tipo, en primer lugar epistemológicos. En ese sentido Floridi subraya que:

The real epistemological problem with big data is small patterns [...] the pressure both on the data nouveau riche [...] and the data old money [...] is to be able to spot where the new patterns with real added-value lie in their immense databases, and how they can best be exploited for the creation of wealth, the improvement of human lives, and the advancement of knowledge ${ }^{3}$. (2014, p. 16)

Esos “pequeños patrones" en el comportamiento de un tipo de traducción emergente son los que pretendemos explorar en este trabajo. Se trata de la traducción colaborativa activista en algunas de sus manifestaciones más recientes, lo que la hace comenzar a deslindarse de la traducción colaborativa activista tradicional o TCA 1.0. Esta última se ha caracterizado, como el activismo también tradicional que le da origen, por el verticalismo político y la disciplina partidista, por una iniciativa y creatividad limitadas de la parte de los traductores, pues la traducción se ha considerado aquí, como antes en los ámbitos religiosos, "a channel of conversion [...] [where] the personal creativity of the translator had to be subordinated to, or subsumed in, the Logos, God's unitary Word"4 (Robinson,

\footnotetext{
${ }^{3}$ El problema epistemológico principal con el big data, son los pequeños patrones [...] el desafío que experimentan ambos volúmenes de información, los nouveau riche [...] y los old money [...] es ser capaces de detectar donde se encuentran, en sus inmensas bases de datos, los nuevos patrones con un real valor agregado y cómo pueden ser explotados mejor, para la creación de riquezas, el mejoramiento de la vida humana y el avance del conocimiento.

Nota del autor: Todas las traducciones en el presente artículo son responsabilidad del autor.

${ }^{4}$ Un medio de conversión, [...] [donde] la creatividad personal del traductor debe estar subordinada o subsumida en el Logos, en la unitaria y divina Palabra.
} 
COLÓN RODRÍGUEZ - La traducción colaborativa activista contemporánea...

1997, p. 182). La TCA 1.0 también se ha caracterizado por un amplio uso de la Web 1.0 como soporte en línea, y es preciso saber que "content creators were few in Web 1.0 with the vast majority of users simply acting as consumers of content" 5 (Cormode y Krishnamurty, 2008). Se hace necesario entonces explicar los adjetivos "colaborativa" y "activista" que acompañan a la traducción que nos interesa, para diferenciarla de esa tradicional con la que coexiste y concurre. La TCA 2.0 - llamémosla así - es entonces colaborativa siguiendo tres definiciones recientes de los estudios de la traducción.

En cuanto a la primera, André Guyon, ha constatado que ella es realizada:

[...] par un groupe de personnes qui travaillent ensemble plutôt qu'isolement. Autrement dit, à la traduction s'ajoutent des volets coordination et échanges entre les participants. $(2010, \text { p. } 33)^{6}$

En efecto existe intercambio y coordinación en la TCA 2.0, pero no es idéntica a la traducción colaborativa en línea en sentido amplio. Guyon se refiere en particular a los proyectos masivos de Wikipedia, Firefox, y otros, que se pueden caracterizar por la fragmentación de textos, traducidos por varias personas. La traducción colaborativa activista que estudiamos aquí se realiza en pequeños colectivos de editores y traductores, y se usan los medios "tradicionales" de comunicación en línea como es el correo electrónico, Google docs, etc. Los textos son traducidos en general por un solo traductor, aún cuando el editor u otro colega pueda revisarlos.

En cuanto a la segunda definición, Pérez-González y Susam-Saraeva en la introducción al número especial de The Translator $^{7}$, consagrado a la traducción no profesional y activista subrayan que se trata de: "individuals not only without formal training in linguistic mediation but also working for free" (2012, p. 151), precisando luego que ese tipo de traducción es realizada por una heterogeneidad creciente de agentes, quienes contribuyen a:

\footnotetext{
${ }^{5}$ Los productores de los contenidos han sido de limitado número en la Web 1.0, con una vasta mayoría de los usuarios de los sitios actuando simplemente como consumidores de contenidos.

${ }^{6}[\ldots]$ por un grupo de personas que trabajan más de conjunto que independientemente. Es decir que a la traducción se suman dimensiones de intercambio y de coordinación entre los participantes.

${ }^{7}$ The Translator, "Non-Professionals Translating \& Interpreting, Participatory and Engaged Perspectives". Vol. 18, n 2, 2012.
} 
COLÓN RODRÍGUEZ - La traducción colaborativa activista contemporánea...

(i) the emergence of new forms of civic engagement in public life, at a time of declining welfare commitment and dwindling state-financing of public services in most developed nations; (ii) the re-configuration of the publishing and media marketplaces, against the ongoing shift from an electronic to a digital culture; and (iii) the consolidation of new paradigms of linguistic, cultural and religious mediation in new sites of cross-cultural contact and interaction - resulting from voluntary migration flows as well as the involuntary displacement and resettlement of populations affected by armed conflict or humanitarian tragedies. (Pérez-González y Susam-Sarajeva, 2012, p. 152) ${ }^{8}$

En la TCA 2.0 participan tanto traductores no profesionales como profesionales y hasta estudiosos de la traducción, de manera que el concepto de heterogeneidad creciente de los agentes, junto a los demás aspectos señalados, son aquí de crucial interés e importancia.

La tercera definición es la de "traducción comunitaria 2.0" que aportó Minako O’Hagan en un número especial de Lingüística Antverpiensia. Ella subraya allí el estrecho vínculo entre las prácticas de la traducción comunitaria y su realización en línea:

[...] community translation is tied to the online community particularly in the specific context of Web 2.0. As such it signifies specific translation practices that are unfolding on the Internet as the central foci. (O’Hagan, 2011, p. 12) ${ }^{9}$

En esta investigación hemos comprobado que la Web 2.0 es en efecto estructurante del funcionamiento de los equipos de traductores colaboradores y activistas, pero igualmente de cada uno de ellos en su labor personal.

La TCA 2.0 es igualmente activista, en el sentido que ya había planteado Maria Tymoczko en su célebre libro Translation in a Postcolonial Context:

[...] translation as a sort of speech act: translation that rouses, inspires, witnesses, mobilizes, incites to rebellion, and so forth. Such translations act in the world and have an activist aspect. [...] translation that has illocutionary and perlocutionary dimensions, that

\footnotetext{
8 “(i) la emergencia de nuevas formas de compromiso cívico en la vida pública, en una era de debilitamiento del bienestar social y de decrecimiento del financiamiento estatal de los servicios públicos en las naciones más desarrolladas; (ii) la reconfiguración de los mercados editoriales y de los medios de difusión masiva, contra el cambio en curso de la cultura electrónica a la digital; y (iii) la consolidación de nuevos paradigmas de mediación lingüística, cultural y religiosa en nuevos sitios de contacto e interacción inter y multicultural, resultado de flujos voluntarios de migración, así como de desplazamientos involuntarios y reasentamiento de poblaciones afectadas por conflictos armados o tragedias humanitarias".

${ }^{9}$ [...] la traducción comunitaria está ligada a la comunidad en línea, particularmente en el contexto específico de la Web 2.0. Como tal, implica prácticas específicas de traducción que se están desarrollando fundamentalmente en Internet.
} 
COLÓN RODRÍGUEZ - La traducción colaborativa activista contemporánea...

actually participates in social movements, that is effective in the world at achieving demonstrable social and political change. $(2000, \text { p. } 26)^{10}$

No obstante, la TCA 2.0, resultado de la combinación de los elementos antes señalados, es también activista en el sentido de reforzar la capacidad de análisis racional de su lectorado, respondiendo a un creciente llamado a una "nueva racionalidad" o sentido común (sanity) en la vida pública, creando las condiciones de hecho para lo que lo que también ha sido llamado la "Slow Politics" (Heath, 2014), o sea, una política gradual o desacelerada, pero sobretodo, y como ha sido señalado en el Anti-Manifiesto de este nuevo movimiento "without forcing people into synchronicity, everyone can be part of a bigger project and at the same time experience her or his own singularity" (Slow Politics AntiManifesto, 2014).

Por todas esas razones, inspira esta investigación la teoría de la complejidad, porque un cambio de paradigma del conocimiento o cambio epistemológico, es desde hace ya un cierto tiempo considerado un modo importante de crecimiento del conocimiento (Kuhn, 1962). La teoría de la complejidad, desarrollada desde hace ya más de 50 años por el sociólogo y filósofo francés Edgar Morin, nos parece adecuada para analizar este contexto, pues se trata justamente de una teoría que además de favorecer un cambio paradigmático, no se propone sustituir ninguna de las precedentes por ser "mejor", o "más avanzada", como ha sido la costumbre pensar en nuestro mundo aún fundamentalmente cartesiano del conocimiento. La complejidad pretende abrir el saber a todas las posibilidades que el intelecto humano es capaz de explorar. Permite también analizar un problema dado, enriqueciéndolo con la perspectiva que nos aportan diversos sectores del saber ${ }^{11}$. Es con ese

\footnotetext{
${ }^{10}[\ldots]$ la traducción como una especie de acto oratorio: traducción que incita, que inspira, que testimonia, que moviliza, que incita a la rebelión y así por el estilo. Tales traducciones juegan un rol determinado en el mundo y poseen una dimensión activista [...] la traducción tiene dimensiones ilocutorias y perlocutorias, que participan en los movimientos sociales y que son eficaces logrando cambios sociales y políticos allí donde tienen lugar.

${ }^{11}$ Por ejemplo, la teoría y la práctica del Nuevo urbanismo, nos permite alejarnos de la visión moderna de construcción urbana que otorga un lugar central al automóvil, con todo lo que ello ha implicado en costos de salud por la polución, o aún del estilo internacional que ha venido borrando la especificidad cultural, nacional o local, de las ciudades, contribuyendo a una globalización de nivelación hacia un sólo estándar. El Nuevo urbanismo busca "rehumanizar" colectivamente el espacio urbano, y al "desistematizarlo", nos recuerda la importancia de la diversidad no sólo para el confort material y psicológico del ser humano, sino también para, desde el propio espacio de vida, favorecer un acercamiento complejo y múltiple a la realidad. Ver: Lerup, (2001). Aún en el campo de la arquitectura, pero más allá de nuestro hábitat planetario tradicional, el proyecto Perséfone nos recuerda que nuestro cambio de época es también de escala del pensamiento y de la acción.
} 
COLÓN RODRÍGUEZ - La traducción colaborativa activista contemporánea...

enfoque que se han elaborado las palabras e ideas que siguen, porque con Eduardo Punset pensamos que el conocimiento, como la vida misma es un proceso "fruto de la diversidad de interacciones, y pareceres diversos y cambiantes" (2010, p. 51).

La sociología del conocimiento, por otra parte, y en particular, la obra de Norbert Elias Compromiso y distanciamiento (1993) nos aporta luz sobre un modo de apreciación de valores que se aleja del tradicional, es decir, de los juicios de carácter político o religioso, para acercarse "al descubrimiento del orden inherente a la relación mutua de los fenómenos" (1993, p. 13-14). El método que él propone es el distanciamiento y en nuestra opinión resulta útil, tanto para la investigación científica, como para el análisis y la calibración del compromiso social. En ese sentido Elias afirma:

[...] la marge individuelle de variation dans la distanciation est limitée par les normes sociales de cette distanciation. Ce sont ces normes qui sont venues s'inscrire dans des formes déterminées de la pensée et du langage relatives à la nature aussi bien que dans la domestication, largement institutionnalisée, de la nature à des fins humaines ${ }^{12}$. $(1993$, p. 12)

Y en un suplemento de 1977 que realiza a la obra citada, Elias agrega:

[...] je ne partage pas la représentation d'une différence quasi existentielle entre «nature » et « culture » ou « histoire ». On peut, dans l'univers observable, reconnaître une hiérarchie de niveaux d'intégration. L'un d'eux, le plus complexe, est le monde humain. Chacun d'eux a des structures propres et requiert donc également ses propres méthodes d'investigation. C'est uniquement une projection de ces différentes méthodes d'intégration, donc de la différence entre sciences de la nature et sciences humaines (ou « sciences de la culture », « sciences historiques », etc.), qui donne l'impression que les domaines d'objets « nature » et « société » sont existentiellement aussi séparés que les sciences de la nature et les sciences de la société ${ }^{13}$. (1993, p. 64).

Ver: <http://www.icarusinterstellar.org/projects/project-persephone/> (Página consultada el 25 de julio de 2013).

${ }^{12}[\ldots]$ el margen individual de variación en la distanciación está limitado por las normas sociales que la rigen. Son esas normas las que han venido insertándose en determinadas formas del pensamiento y del lenguaje relativas a la naturaleza, así como en la domesticación humana de la naturaleza, ya ampliamente institucionalizada.

${ }^{13}$ [...] no comparto la representación de una diferencia casi existencial entre "naturaleza" y "cultura" o "historia". En el universo observable podemos reconocer una jerarquía de niveles de integración. Uno de ellos, el más complejo, es el ámbito humano. Cada uno de ellos tiene estructuras propias y requiere por ende de sus propios métodos de investigación. Es tan sólo una proyección de esos diferentes métodos de integración, es decir, de la diferencia entre ciencias de la naturaleza y ciencias humanas (o "ciencias de la cultura", "ciencias históricas", etc.), lo que da la impresión que los ámbitos de los objetos "naturaleza" y "sociedad" están tan existencialmente separados, como las ciencias de la naturaleza y las ciencias de la sociedad". 
COLÓN RODRÍGUEZ - La traducción colaborativa activista contemporánea...

Esta afirmación nos permite constatar dos aspectos importantes, primero, el acercamiento complejo de Elias a la cuestión del conocimiento humano y segundo, afirmar con él que los métodos inter, multi, y transdisciplinarios en las ciencias constituyen un "regreso" 14 a una lógica epistemológica de sistemas. Regreso que tiene lugar en un momento histórico rico en micro y macro descubrimientos, que permiten contar con un mejor panorama del conjunto de los fenómenos naturales (incluyendo el cuerpo humano) en nuestro espacio-tiempo y del universo conocido.

Pero lo que puede aplicarse al conocimiento, se puede aplicar también a la acción social, porque Elias al reconocer el principio complejo dialógico ${ }^{15}$ de los conceptos de autonomía y heteronomía de la voluntad ${ }^{16}$, nos hace ver también que ellos ni son estáticos ni son absolutos, sino que funcionan en interacción permanente, a la escala tanto de sistemas como de unidades. Sin embargo, es relevante tener en cuenta una importante tendencia de este binomio autonomía-heteronomía y Elias la formula como sigue:

Plus l'engagement est grand et plus la tendance à des jugements hétéronomes s'accroît; plus grande sera la distanciation, plus grande sera la tendance à des jugements de valeur autonomes ${ }^{17}(1993$, p. 57)

Diríamos entonces que el traductor puede y debe ver las relaciones de equilibrio y de dominación entre autonomía y heteronomía en las que su actividad se desarrolla, en particular cuando esta se inserta en el fragor de los conflictos sociales.

Por otra parte, la traductología ha sido y continua siendo una ciencia social que no ha terminado de "cristalizar", según los criterios que para las ciencias se han sostenido tradicionalmente. En la frontera entre tantas otras disciplinas "consagradas" que la precedieron y que le hacen la competencia, ese ha sido su sino, pero también su fortaleza.

\footnotetext{
${ }^{14}$ Entre comillas, pues hago referencia aquí a las cosmovisiones holísticas de las culturas orientales, mejor estudiadas y asimiladas hoy por hoy en Occidente e integradas de manera compleja con lo que el pensamiento racional individualista y disyuntivo cartesiano ha también aportado al conocimiento.

${ }^{15}$ Morin lo clasifica como sigue: «Le principe dialogique nous permet de maintenir la dualité au sein de l'unité. Il associe deux termes à la fois complémentaires et antagonistes » (2005 [1990]: 99) (El principio dialógico nos permite mantener la dualidad en el seno de la unidad. El mismo asocia dos términos que resultan ser complementarios y antagonistas a la vez).

${ }^{16}$ Elias nos dice: «Il s'agit toujours d'un degré plus ou moins élevé d'autonomie ou d'hétéronomie dans les connaissances, donc de différentes rapports d'équilibre et de domination entre ceux deux pôles » (Se trata siempre de un grado más o menos elevado de autonomía o de heteronomía en el conocimiento, es decir, de diferentes relaciones de equilibrio y de dominación entre esos dos polos) (1993: 57).

${ }^{17}$ Mientras más importante es el compromiso, mayor será la tendencia a juicios de valor heterónomos. Mientras más importante es la distanciación, mayor será la tendencia a juicios de valor autónomos.
} 
COLÓN RODRÍGUEZ - La traducción colaborativa activista contemporánea...

Numerosos trabajos testimonian el recurrente interés de nuestra disciplina por la interdisciplinariedad (Wilss, 1999; House, 2013; O'Brien, 2013; Saldanha y O'Brien, 2013). Quizás la razón por la cual la traductología ha podido lanzarse a aventuras intelectuales de este tipo, a las cuales otras ciencias sociales han sido más reacias, sea la rigidez institucional que las últimas han ido adquiriendo y que la traductología ha podido evitar.

Dos ejemplos recientes de esta última afirmación son los siguientes: La traductología ha sido una de las primeras disciplinas en adoptar las numerosas teorías que han venido apareciendo en las ciencias sociales. Todos los que trabajamos en esta área conocemos la diversidad de turns que se han operado en ella en los últimos decenios, pero hoy, hasta la teoría de la complejidad, que no por tener ya decenios de existencia ha sido ampliamente incorporada a estudios sociales, acaba de serlo a un ambicioso y profundamente argumentado estudio de la relación entre traducción y desarrollo, vinculando dos campos de estudio antes desconectados y siendo desarrollado ese estudio bajo la renovadora visión teórica de la complejidad. El trabajo de Kobus Marais, Translation Theory and Development Studies: A Complexity Theory Approach (2013), es un primer paso en ese sentido, y el será sin dudas apreciado por todos aquellos que ya antes habían señalado la importancia del vínculo entre la traducción y los sistemas complejos (Even-Zohar 2005 y Tuylenev, 2011), por citar tan sólo dos de los principales autores que han abordado estos temas.

En segundo lugar, nuestra disciplina ha sido también capaz de cuestionar su propio objeto de estudio (la traducción profesional), como testimonian los editores del número de The Translator ya citado:

Translation Studies potentially addresses a much larger conceptual and discursive area. One can even argue that it is professional - rather than non-professional - translation that should be taken as the exception within the wider context of translation. (Pérez-González y Susam-Sarajeva, 2012, p. 157) ${ }^{18}$

Esas son algunas de las razones por las que yo decidí salirme del estrecho marco de la historia académica — mi vocación y estudios iniciales — para entrar de lleno en el de la

\footnotetext{
${ }^{18}$ Los Estudios de la traducción potencialmente se dirigen hacia un área conceptual y discursiva más amplia. Se puede incluso argumentar que es la traducción profesional - en lugar de la no profesional - la que debe ser considerada como la excepción, en un contexto más vasto de la traducción.
} 
COLÓN RODRÍGUEZ - La traducción colaborativa activista contemporánea...

traducción y su estudio, esta última siendo mi profesión y objeto de investigación actuales. La historia sin embargo permanece en el centro de interés, pues es una parte de la historia contemporánea de la traducción la que constituye el objeto de este estudio. Se trata de un nuevo tipo de traducción colaborativa activista, realizada fundamentalmente por traductores no profesionales, en dos países muy singulares de las Américas: Canadá y Brasil, con espacios geográficos, demográficos y culturales entre los mayores del continente y del mundo, y en el centro - con matices claro está — de la geopolítica continental y mundial.

El interés en este tópico está fuertemente motivado por mi historia personal, pues siendo cubano de nacimiento, he vivido la mitad de mi vida sometido a un torrente de persuasión ideológica, originado por el proceso político-social que comenzó en 1959 y que se vio fortalecido por las alianzas geopolíticas que el gobierno cubano hiciera desde muy temprano en década de 1960, al cambiar radicalmente el curso de la historia de la isla. Para bien y para mal, como todo fenómeno social, la imposición de un pensamiento único unió al país alrededor de un programa que dio, es cierto, algunos relevantes resultados, pero que no tuvo, ni ha tenido hasta hoy, ni rival, ni crítica legales, con las consecuencias que conocemos bien. Es por ello que los casos de Canadá y de Brasil en el campo de la traducción y específicamente de la traducción colaborativa activista, pueden contribuir a la reflexión sobre cómo los traductores pueden ser agentes de cambio y de qué cambio, en nuestras tierras americanas.

También es preciso destacar — para acercarnos a las razones de selección del corpus - , que el desarrollo de las nuevas tecnologías de la información, Internet y las redes sociales, en vivo y virtuales (o sea, en línea), han venido cambiando de manera exponencial la silueta política de innumerables países, tanto en el primer mundo, como en el emergente ${ }^{19}$, o en el tercer mundo ${ }^{20}$. Todos hemos sido testigos cercanos o lejanos del

\footnotetext{
${ }^{19}$ El segundo mundo desapareció con la caída del Bloque del Este, pero ha venido a tomar su lugar el grupo de países emergentes, entre los cuales los pertenecientes al BRIC (Brasil, Rusia, India, China), es el más notorio.

${ }^{20} \mathrm{El}$ impacto ha sido también considerable en el campo de la investigación científica, pues como señala el profesor Andrew Maynard: "the internet is flooded with a wealth of information which is richer than could ever be imagined 20 years ago. Researchers have access to vast arrays of new information in their own field, as well as new findings in other disciplines. The result is a cross-fertilization that is driving the generation of new scientific knowledge and technology innovation at an unprecedented rate" (Internet ofrece una cantidad tal de información, que sobrepasa toda la que se pudo imaginar hace 20 años. Los investigadores tienen acceso a un amplio surtido de nuevas informaciones en sus campos, así como a los descubrimientos de otras disciplinas. El resultado es una fertilización cruzada que está promoviendo una generación de nuevos conocimientos científicos y de innovación tecnológica, a un ritmo sin precedentes) (2009).
} 
COLÓN RODRÍGUEZ - La traducción colaborativa activista contemporánea...

11-M de Madrid, de las primaveras árabes, del movimiento occupy, por cierto una iniciativa canadiense $^{21}$, del movimiento estudiantil quebequense del 2012 y mucho más recientemente de la protesta social brasileira del 2013. En todos ellos ha sido decisivo el uso de los nuevos medios de comunicación social para la movilización y la acción activista $^{22}$. Sin embargo, el viejo activismo partidista del siglo XX, ideologizado, sectario y exclusivista, amén de particularmente metafórico a nivel retórico y dialéctico a nivel cognitivo, que hemos llamado 1.0, se ha visto, con cada nuevo fenómeno social que ha tenido lugar, poco a poco relegado por un nuevo tipo de activismo que parte de la sociedad civil, de ella se nutre y a ella regresa, y que hemos llamado 2.0. Este último se viene caracterizando por la pluralidad ideológica de sus actores, por una temporalidad cambiante del compromiso político, por una retórica de tendencia metonímica y una gnosis dialógica. La traducción colaborativa activista 2.0 posee también, al menos en germen, estas características, siendo un fenómeno sintomático de los procesos globales.

La traductología contemporánea comienza a interesarse ya de manera general en estos procesos globales y el tema comienza a hacerse sentir en las publicaciones de nuestra disciplina $^{23}$. Los tres aspectos señalados como fundamentales en este proceso evolutivo han sido expuestos a la hora de explicar el carácter "colaborativo" de la traducción que nos ocupa. Esta evolución constituirá pues el nudo central del presente texto y comenzaré con el contexto que precede al caso canadiense, que es también útil para el brasileño que le sigue. Luego analizaré un breve corpus seleccionado de ambos sitios estudiados y finalmente propondré las conclusiones.

\section{Contexto y proyección de dos proyectos de traducción colaborativa activista}

Niemand hat das Recht zu gehorchen - Nadie tiene derecho a obedecer

HANNAH ARENDT

\footnotetext{
${ }^{21}$ Ver el sitio de Adbusters en: < https://www.adbusters.org/> (Página consultada el 25 de julio del 2013).

${ }^{22}$ Numerosos autores han dado fe de ello en el caso canadiense: Williams (1977), Keane (1991), y Curran (2002), citados por (Kozolanke (ed.), 2012:2). En este último texto se llega a decir: "Alternative media can thus represent possibilities for progressive social change, or counter-hegemonic transformation, and can, at times, be considered both media and social movement" (Los medios alternativos pueden representar posibilidades de cambio social progresista, o transformación anti-hegemónica, y a veces, hasta pueden ser considerados a la vez, medios y movimientos sociales). (2012: 3).

${ }^{23}$ Recordemos las obras citadas al principio de este trabajo, a saber: The Translator (dos números, el primero en 2007 y el más reciente en 2012) y Linguistica Antverpiensia (un número en 2011).
} 
COLÓN RODRÍGUEZ - La traducción colaborativa activista contemporánea...

La frase de Hannah Arendt que encabeza esta sección sintetiza quizás mejor que ninguna otra, el espíritu de estos nuevos proyectos de activismo traductivo. Veamos por qué.

\section{I.1 La traducción activista en Canadá entre la Web 1.0 y la 2.0}

La historia de la traducción activista en Canadá y en particular la de la traducción colaborativa activista, que es un fenómeno más reciente, está aún por escribir en su vasta gama de matices y casos, pero se pueden trazar aquí muy brevemente algunos rasgos característicos de este proceso. Comenzaremos describiendo y analizando dos proyectos de traducción militante que muestran características diferentes al caso que nos ocupa, para comprender mejor como se ha llegado a él.

\section{I.1.1 GlobalResearch.ca y Mondialisation.ca}

Este primer ejemplo está conformado por dos sitios que funcionan en simbiosis, ya que ambos son dirigidos por un mismo Centre de recherche sur la mondialisation, que se encuentra en Montreal y que fue fundado y dirigido por el profesor universitario Michel Chossudovsky. La versión inglesa fue creada en el 2001, “dos días antes del 11 de septiembre", como se anuncia en su presentación:

The Global Research website was established on the 9th of September 2001, two days before the tragic events of September 11. Barely a few days later, Global Research had become a major news source on the New World Order and Washington's "war on terrorism,"24.

Mondialisation.ca, versión francófona, pero autónoma del primero, le siguió en el 2006. En el 2007 aparecen las primeras traducciones de artículos de ambos sitios, en español, portugués y alemán. En el 2008 surgen traducciones en árabe, italiano y serbio. En junio del 2010 es lanzado The Global Research TV Website y finalmente en noviembre del 2012 comienza a difundir el proyecto radial The Global Research News Hour.

\footnotetext{
${ }^{24}$ URL: <http://www.globalresearch.ca/about> (Página consultada el 15 de abril de 2013). El sitio de Global Research se fundó el 9 de septiembre de 2001, dos días antes de los trágicos sucesos del 11 de setiembre. Apenas unos días después, Global Research se ha convertido en una fuente mayor de noticias sobre el Nuevo Orden Mundial, y la "guerra contra el terrorismo" de Washington.
} 
COLÓN RODRÍGUEZ - La traducción colaborativa activista contemporánea...

El objetivo original de los dos sitios no era la traducción como tal, sino compartir información alternativa - e ideológicamente definida - , a aquella de los grandes medios de información, o como lo escribe el propio Chossudovsky: "In an era of media disinformation, our focus has essentially been to center on the "unspoken truth" (Chossudovsky, 2012) ${ }^{25}$. La traducción con todo se hace muy visible en este proyecto, en razón del deseo de difundir en otras lenguas que no fuesen ni el inglés ni el francés textos sobre la actualidad, portadores de una visión crítica del orden mundial actual. El profesor Chossudovsky imprime al proyecto una connotación carismática y estos sitios tienen una red de relaciones, poseen una retórica ${ }^{26}$ y funcionan siguiendo parámetros clásicos del activismo tradicional que ya hemos explicitado antes.

Siendo éstos proyectos típicos de la Web 1.0, se prioriza en ellos la crítica del poder hegemónico mundial, dejando sin embargo en la sombra los lados oscuros de la resistencia a ese poder y a veces esa resistencia puede ser simplemente totalitarismo ordinario ${ }^{27}$. Otro aspecto importante es la utilización abundante de terminología marcada ideológicamente, poseedora de una emotividad e intencionalidad persuasiva predominantemente implícita similar a la de la publicidad comercial -, con el objetivo de lograr la aceptación y adhesión a los postulados vehiculizados por el texto y poca o escasa vocación de fomentar la discusión o la crítica hacia el autor de los argumentos aportados ${ }^{28}$. El activismo 1.0 tuvo y mantiene como objetivo movilizar a grandes cantidades de personas en torno a fuerzas que son las encargadas de liderar el movimiento. Este activismo heredó del proselitismo religioso milenarista que le antecede similares métodos y un mismo objetivo final, que es subordinar las masas al dictado de hermeneutas, religiosos o laicos.

\footnotetext{
${ }^{25}$ En una era de desinformación mediática, nuestro énfasis ha sido concentrarnos en las "verdades ocultadas".

${ }^{26}$ Global Research, acaba de publicar un artículo sobre los sucesos vinculados a Charlie Hebdo, el título del cual es un ejemplo clásico de formulación metafórica: «Paris Shooters Just Returned from NATO’s Proxy War in Syria ». El término «Proxy War» es una metáfora del campo militar, ampliamente utilizada por políticos luego que Zbigniew Brzezinski la retomara para designar los conflictos de la « Guerra Fría », siendo esta última igualmente ¡una metáfora! Ver: http://www.globalresearch.ca/paris-shooters-just-returned-fromnatos-proxy-war-in-syria/5423517, (Página consultada el 11 de enero de 2015).

${ }^{27}$ Ver por ejemplo el artículo del profesor Chossudovsky: "The Threat of Nuclear War, North Korea or the United States?", donde se ignora u omite mencionar los horrendos crímenes y atentados a los derechos humanos cometidos permanentemente en ese país asiático. Ver en: <http://www.globalresearch.ca/the-threatof-nuclear-war-north-korea-or-the-united-states/5343793>. (Página consultada el 25 de julio del 2013).

${ }^{28}$ En este sentido es interesante ver y analizar desde el punto de vista de análisis del discurso, el reportaje: "The Meaning of the Brazilian Protest Movement", URL: < http://tv.globalresearch.ca/2013/07/meaningbrazilian-protest-movement>, donde James Corbett, Michel Chossudovsky y Pepe Escobar exponen, únicamente "entre expertos", sus respectivos análisis de la crisis brasileña de 2013. (Página consultada el 25 de julio del 2013).
} 
COLÓN RODRÍGUEZ - La traducción colaborativa activista contemporánea...

\section{I.1.2 Rouge Squad}

Sitio de traducción activista, en particular del francés al inglés y también en el sentido contrario, fue originado al calor de la ola de protestas estudiantiles de Quebec en 2012, y surge como un proyecto colectivo de los estudiantes de segundo ciclo de la Universidad Concordia de Montreal ${ }^{29}$. El proyecto se autodefinía como "tactical translation team" ${ }^{30}$, es decir, que ejecutaba tareas de traducción para las organizaciones estudiantiles que dirigieron el movimiento de protesta, en particular para la coordinadora CLASSE. ${ }^{31}$

Desde el propio título del sitio se puede apreciar que se trata de un grupo militante con una reconocible ideología de la izquierda internacional, coherente con una disciplina históricamente conocida como "partidista". La terminología y la puesta en escena del sitio dan fe de ello de manera exhaustiva. Rouge Squad fue activo en particular durante los meses álgidos de la protesta estudiantil del 2012. Este proyecto funcionó sobre la base del voluntariado. A medida que el movimiento perdió intensidad, en particular después que las elecciones de septiembre del 2012 en la provincia de Quebec, sacaron del poder a los liberales y lo cedieron a los pequistas, de ideología independentista, las prioridades de este grupo cambiaron. El último post-traducción data del 3 de diciembre del 2012. El sitio no obstante sigue en línea y ha incorporado una página en lengua árabe, que aunque poco desarrollada, parece ser un esfuerzo por diversificar el impacto del mismo. ${ }^{32}$

Rouge Squad sería entonces una segunda variante de un proyecto reciente de traducción colaborativa activista. Surgido en un contexto local específico y para responder a necesidades de organizaciones militantes estudiantiles, jóvenes que trabajan colectivamente, pero que se encuentran enmarcados en una disciplina política tradicional, todo ello parece indicar un caso de transición entre el militantismo traductivo del siglo XX y el que comienza a implantarse en el nuestro, que pasamos a presentar.

\footnotetext{
${ }^{29}$ Son en lo fundamental traductores no profesionales, aunque universitarios. Esta información nos la aporta Anna Sheftel, fundadora de Translating the printemps érable, en entrevista realizada por Clara Foz y el autor de estas líneas el 16 de octubre del 2012.

${ }^{30}$ Subtitulo del sitio. URL: < http://rougesquad.org/> (Página consultada el 13 de febrero del 2013).

31 Coalition large de l'Association pour une solidarité syndicale étudiante. URL: <http://www.bloquonslahausse.com/laclasse/a-propos/> (Página consultada el 25 de julio del 2013).

${ }^{32}$ Es importante tener en cuenta que la Universidad Concordia es una de las dos universidades anglófonas de Montreal, donde estudian miles de inmigrantes de filiación anglófila, así como numerosos estudiantes extranjeros, en particular del Medio Oriente.
} 
COLÓN RODRÍGUEZ - La traducción colaborativa activista contemporánea...

\section{I.1.3 Translating the printemps érable}

Traduciendo la primavera de arce $e^{33}$ surge el 19 de mayo del 2012, como respuesta a lo que sus fundadores consideraron una "extremadamente pobre cobertura" de los medios anglófonos canadienses, de lo que sobre el conflicto estudiantil se publicaba en los medios francófonos de ese país, en particular en Quebec, que era la provincia afectada, pero también en las redes sociales en Internet. Desde el título mismo del proyecto se advierte el deseo de establecer, a través de la traducción, un vínculo de conocimiento e interacción entre las dos lenguas oficiales de Canadá: el inglés y el francés, que son al mismo tiempo los idiomas de sus dos culturas mayoritarias y las dos comunidades políticas más decisivas en el panorama nacional. Como se expresa en el texto de presentación del sitio:

Translating the printemps érable is a volunteer collective attempting to balance the English media's extremely poor coverage of the student conflict in Quebec by translating media that has been published in French into English ${ }^{34}$.

Quedaba claro desde el principio que serían en lo fundamental traducciones no profesionales (volunteer collective) y por eso se llamaba a los lectores a señalar los errores de traducción que pudieran ocurrir, e igualmente a leer y a difundir los textos "in the spirit

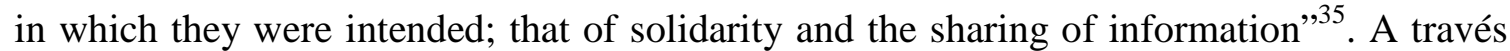
de la terminología utilizada podemos observar el nivel de implicación política del proyecto con los estudiantes, pero es necesario señalar que esa solidaridad transparentemente asumida no implicó silenciar a la otra parte en el conflicto, pues varias traducciones fueron hechas de artículos y de medios de prensa que desaprobaban las manifestaciones estudiantiles. Ello, en nuestra opinión, es uno de los síntomas de ese nuevo activismo traductivo que estudiamos aquí.

Anna Sheftel, fundadora del proyecto, nos ha dicho en entrevista que a poco de comenzar el sitio, se tornó "viral", reuniendo a varios colaboradores frecuentes (sobretodo

\footnotetext{
${ }^{33}$ El juego de palabras anglo-francés del título hace referencia a las primaveras árabes, por el espíritu de las reivindicaciones. Los sucesos en Quebec además también tuvieron lugar en primavera. Se hace referencia igualmente al hecho de que esta provincia canadiense se reconoce internacionalmente, entre muchos otros productos, por su producción del azucarado sirope de arce.

${ }^{34}$ Translating the printemps érable es un colectivo voluntario que procura equilibrar la extremadamente pobre cobertura de los medios anglófonos del conflicto estudiantil en Quebec, traduciendo al inglés artículos de prensa francófonos.

${ }^{35}$ En el espíritu en que fueron originados, es decir, en el de solidaridad y en el de compartir la información.
} 
COLÓN RODRÍGUEZ - La traducción colaborativa activista contemporánea...

amateurs y algunos profesionales de la traducción) y a otros menos frecuentes, pero asiduos. Anna subrayó que:

C'était moi qui l'a faite, mais c'était évident qui avait beaucoup de gens qui voulait faire la même chose. 24 heures après il y avait même des étrangers qui voulait aider [...] c'est [devenu] "viral" immédiatement ${ }^{36}$.

Es decir, el momento elegido tuvo mucho que ver con ese impacto inmediato, pues el movimiento estudiantil y la reacción de la sociedad en Quebec en torno a este tema se encontraban en su momento más álgido, de manera que el vivo interés de un importante público anglocanadiense, pero también internacional, podía vehicularse a través de Translating the printemps érable en lengua inglesa.

En el gráfico que aparece a continuación puede apreciarse ese impacto concreto e inmediato que recibió el sitio. Están cuantificados aquí los totales de notas de los lectores según los totales de traducciones publicadas por cada mes de existencia del sitio y durante un año. Le di prioridad a este criterio y no a las visitas al sitio, que es el criterio tradicional de popularidad de sitios Web, por dos razones: 1. No dispongo de las estadísticas de visitas al sitio. 2. Las notas de los lectores, en mi opinión, constituyen un síntoma mucho más fiable del interés en un proyecto de este tipo, por la interacción que implica y por el hecho de que resultan verificables por todo lector interesado.

\section{Gráfico $\mathbf{N}^{\mathbf{0}} .1$}

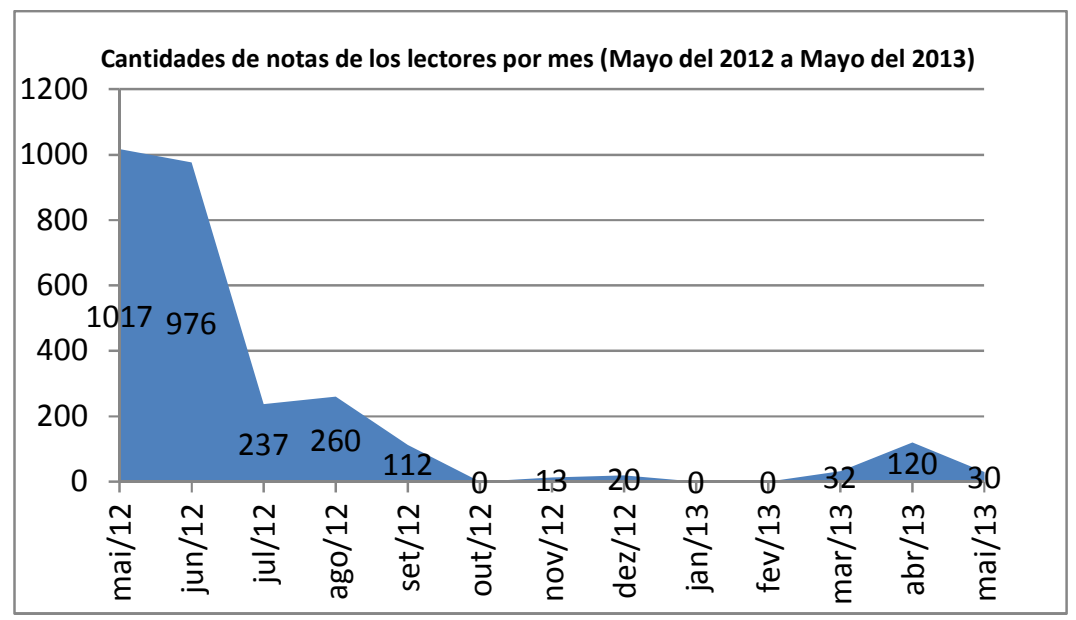

\footnotetext{
${ }^{36}$ Fui yo quien lo hizo, pero era evidente que había muchas personas que querían hacer lo mismo. 24 horas después hasta extranjeros deseaban colaborar [...] se [convirtió en algo] "viral” inmediatamente.
} 
COLÓN RODRÍGUEZ - La traducción colaborativa activista contemporánea...

\section{I.2 Rio+20}

Los antecedentes de activismo traductivo en Brasil son numerosos y han sido recogidos parcialmente en monografías y artículos traductológicos. Nos limitaremos aquí a citar esas fuentes ${ }^{37}$ sin entrar de lleno en su análisis, que proseguiremos en próximos estudios.

El portal Rio +20 por su parte, se inserta fundamentalmente en lo que ya hemos calificado de activismo traductivo 1.0, sin embargo, como el caso canadiense de Translating the printemps érable, este proyecto presentó nuevas facetas tanto por la pluralidad de enfoques que promovió, como por la aplicación profusa y precisa de las nuevas herramientas que ofrece hoy en día la Web 2.0. Se trataba de un esfuerzo internacional, coordinado por la Asociación francesa Traversées ${ }^{38}$ y financiado por la Fundación suiza Charles Lépold Mayer ${ }^{39}$, ejecutado en cuatro idiomas: el portugués, el francés, el inglés y el español por un grupo internacional de traductores ${ }^{40}$, que fue creado para dar soporte a la Cumbre de los pueblos Rio+20 celebrada en julio del 2012, y en particular para fomentar el debate entre los participantes en esa cumbre. Todo ello, a través de textos portadores de una amplia gama de pensamientos y de filosofías de la acción social, que caracterizan al movimiento alternativo del Fórum Mundial. De modo que se rompió aquí con el esquema tradicional de promoción de una sola ideología, aún cuando es evidente una confluencia general de sus participantes en tomas de posición de carácter anticapitalista. Se constata igualmente el tratamiento de un grupo específico de temas de la problemática internacional $^{41}$, pues se discute un amplio eje temático que va desde los derechos del hombre, pasando por la arquitectura del poder, la democracia y la gobernabilidad mundial, hasta la producción, la distribución y el consumo de los bienes comunes, sin olvidar una amplia gama de tópicos ambientales y relativos al cambio climático. Un funcionamiento colegiado entre sus diferentes grupos de promoción es

\footnotetext{
${ }^{37}$ Ver en particular: Milton (2004, 2010), así como también Blume y Peterle (2013).

${ }^{38}$ Ver: http://www.traversees.org/ (Página consultada el 27 de julio del 2013).

${ }^{39}$ Ver: http://www.fph.ch/?lang=fr (Página consultada el 27 de julio del 2013).

${ }^{40}$ Ver: http://rio20.net/fr/mentions-legales/ (Página consultada el 27 de julio del 2013).

${ }^{41}$ Como es predominantemente el caso de Global Research y Mondialisation antes aquí presentados, quienes se concentran en la temática del Nuevo Orden Mundial y la Guerra contra el terrorismo de Washington. URL: http://www.globalresearch.ca/about (Página consultada el 27 de julio del 2013).
} 
COLÓN RODRÍGUEZ - La traducción colaborativa activista contemporánea...

también un elemento que va en la dirección de un acercamiento hacia las nuevas formas del activismo traductivo contemporáneo que estamos analizando.

\section{Corpus y análisis}

L'utilisation d'outils informatiques apporte des éclairages différents sur les termes et leur environnement linguistique ... [permettant] de rompre avec la lecture linéaire qui caractérisait la recherche classique » (Marie-Claude L'Homme, 2004) ${ }^{42}$.

La selección de los textos está directamente relacionada con momentos altamente significativos para los movimientos sociales que les dieron origen. En el caso de Translating the printemps érable es el editorial del periódico quebequense Le Devoir, titulado "Loi 78 - Abus de pouvoir", del 19 de mayo del $2012^{43}$ relativo a la aprobación de la ley 78 que el gobierno liberal de Jean Charest propuso a la asamblea nacional de Quebec para contener y reprimir el movimiento estudiantil. En el caso del portal Rio+20 es la "Declaración final de la Cumbre de los Pueblos de Rio+20 por la justicia social y ambiental", del 15 al 22 de julio del 2012, que "sintetiza los principales ejes discutidos durante las plenarias y asambleas, [...] así como los principales ejes de lucha para el próximo período" 44 .

Es una de las apuestas de este estudio establecer que en este tipo de documentos se encuentra una mayor concentración de términos y/o frases ideológicamente marcados, asegurando una mayor representatividad de los fenómenos estudiados aquí. No obstante, seguiremos incorporando otros textos para poder validar o contestar la hipótesis inicial, que contiene dos aspectos, es decir, que la traducción no sólo interactúa con los discursos presentes en el original de manera no siempre equivalente, sino que ella también puede intensificar o amenguar la carga ideológica del texto inicial, dependiendo de la actitud personal del traductor hacia la causa que vehicula el texto original, adaptando y ajustando

\footnotetext{
${ }^{42}$ La utilización de herramientas informáticas aporta esclarecimientos diferentes sobre los términos y su entorno lingüístico... [permitiendo] romper con una lectura linear que caracterizaba a la investigación clásica.

${ }^{43}$ Ver: <http://www.ledevoir.com/politique/quebec/350475/loi-78-abus-de-pouvoir〉. La traducción inglesa de Translating the printemps érable, objeto de estudio aquí, se encuentra en: <http://translatingtheprintempserable.tumblr.com/post/23376220958/bill-78-abuse-of-power-le-devoir>. (Páginas consultadas el 14 de enero de 2015).

44 Ver: <http://rio20.net/propuestas/declaracion-final-de-la-cumbre-de-los-pueblos-en-la-rio20/>. (Página consultada el 21 de enero de 2013).
} 
COLÓN RODRÍGUEZ - La traducción colaborativa activista contemporánea...

la terminología del original a las necesidades o usos del usuario de destino, amén de la carga cultural que traductor y receptor presuponen.

\section{II.1 Fichas de temas con su contexto}

Luego de haber procesado con la ayuda del programa SynchroTerm ${ }^{45}$ de Terminotix, un amplio listado de términos que permitió detectar los temas más relevantes presentes en ambos corpus, tanto desde un punto de vista cuantitativo como cualitativo, se pudieron crear fichas terminológicas con sus contextos respectivos.

En el corpus de Translating existen asociaciones de términos que forman el tema central del documento, un primer ejemplo de esos temas se observa a través del ideologema loi (ley), fuertemente asociado con abus (abuso) en la primera ficha.

\section{Ficha 1}

Source Entry Abus de pouvoir

Target Entry Abuse of Power

Domain traduction

Subject Translating the printemps érable

Source Context * Loi 78 - Abus de pouvoir [1] * Les seuls mots qui peuvent qualifier la loi numéro 78 adoptée hier par

l'Assemblée nationale pour assurer un retour aux études sont ABUS DE POUVOIR. [1]

Target Context* Bill 78 - Abuse of Power (Le Devoir) [1] * The only words that can describe Bill 78, which was adopted

yesterday by the National Assembly to ensure a return to studies are: ABUSE OF POWER. [1]

Source Occurrence 2

Target Occurrence 2

Description traduction activiste

Para poder desviar, o incluso cambiar la connotación establecida por la sociedad para este término ${ }^{46}$, al menos en este contexto específico, se constata que tanto el original como la traducción hacen una utilización de las mayúsculas que posee un objetivo persuasivo evidente: convencer al lector de la injusticia cometida por el órgano legislativo quebequense de ese momento.

\footnotetext{
${ }^{45}$ Ver:

<http://www.terminotix.com/index.asp?name=SynchroTerm\&content=item\&brand=4\&item=7\&lang=fr >. (Página consultada el 28 de julio del 2013).

${ }^{46}$ Existe un consenso en las herramientas de referencia francófonas en cuanto a la acepción del término: "Règle, prescription établie par l'autorité souveraine d'un État et imposée à toute la société" (Norma, prescripción establecida por la autoridad soberana de un Estado e impuesta a toda la sociedad). Antidote HD. "Prescription établie par l'autorité souveraine de l'État, applicable à tous et définissant les droits et les devoirs de chacun" (Prescripción establecida por la autoridad soberana del Estado, aplicable a todos y pudiendo definir los derechos y deberes de cada cual). Larousse en línea. (Página consultada el 12 de febrero de 2013).
} 
COLÓN RODRÍGUEZ - La traducción colaborativa activista contemporánea...

Un segundo ejemplo de los temas tratados aparece en la ficha 2, a través del ideologema ${ }^{47}$ droits, que tanto en plural, como en singular y en colocación con diferentes calificativos señala el tipo de discurso que se encuentra presente en el texto. Una de estas colocaciones más connotada ideológicamente es droits fondamentaux (derechos fundamentales), que remite a la Charte des droits et libertés de la personne ${ }^{48}$ (Carta de derechos y libertades de la persona), donde esos términos en colocación, se encuentran en cuatro casos y donde el término droit (derecho) tiene 98 ocurrencias, en un total de 11.080 palabras.

De manera que hasta aquí hemos podido, primero: identificar las fuentes textuales del discurso que debe traducirse y segundo: identificar el tipo de discurso ideológico al uso, que en el caso presente es el discurso democrático, tal y como se ha desarrollado en la sociedad quebequense contemporánea.

\section{Ficha 2}

Source Entry droits fondamentaux

Target Entry fundamental rights

Domain traduction

Subject Translating the printemps érable

Source Context * Le respect des droits fondamentaux fait partie de nos valeurs. [1] * Pour les groupes sociaux, c'est l'occasion

saisie par l'État pour miner des droits fondamentaux. [1]

Target Context * A respect for our fundamental rights is part of our values. [1] * For various social groups, this is an opportunity

that the state has seized to undermine fundamental rights. [1]

Source Occurrence 2

Target Occurrence 2

Description traduction activiste

Un tercer ejemplo de tema gira en torno al ideologema raison (razón), en la ficha 3, el cual aporta luz sobre una idea clave que contiene el documento analizado. Para los

\footnotetext{
${ }^{47}$ Una útil definición del término lo ofrece el diccionario de Carlos Ceia: "Os ideologemas funcionam como os topoi aristotélicos, constituindo os princípios responsáveis pela coesão e coerência do discurso social e cultural, o que nos garante ao mesmo tempo a compreensão da própria ideologia do discurso. Nas teorias de Mikhail Bakthin sobre a narrativa, o ideologema designa aqueles termos ou expressões que induzem a uma determinada ideologia" (Los ideologemas funcionan como los topoi aristotélicos, constituyendo los principios responsables por la cohesión y la coherencia del discurso social y cultural, lo cual nos garantiza simultaneamente la comprensión de la propia ideología del discurso. En las teorías de Mijaíl Bajtín sobre la narrativa, el ideologema designa aquellos términos o expresiones que inducen una determinada ideología). Ver: $\langle$ http://www.edtl.com.pt/index.php?option=com_mtree\&task=viewlink\&link_id=406\&Itemid=2 >. (Página consultada el 28 de julio de 2013).

${ }^{48}$ Adoptada en 1975.

URL: <http://www2.publicationsduquebec.gouv.qc.ca/dynamicSearch/telecharge.php?type=2\&file=/C_12/C1

2.HTM >. (Página consultada el 12 de febrero de 2013).
} 
COLÓN RODRÍGUEZ - La traducción colaborativa activista contemporánea...

autores del editorial de Le Devoir, es la vía a seguir en el conflicto estudiantil, es decir, una tercera vía de moderación, de negociación y de relajamiento de la tensión social.

Ficha 3

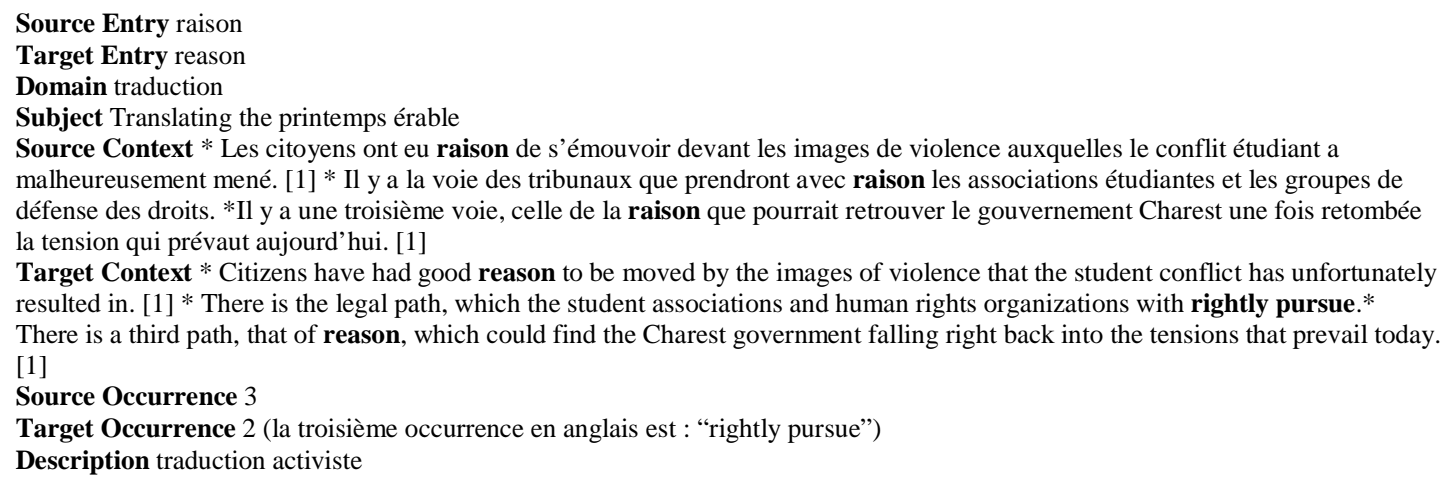

El ejercicio realizado nos ha mostrado que el corpus canadiense es representativo del discurso democrático, en los términos en que se ha materializado en Quebec, que se inspira de la Charte des droits et libertés de la personne de Quebec y que este discurso promueve una vía de moderación y de negociación en la resolución del conflicto social en curso.

En el corpus de Rio +20 ciertas asociaciones de términos forman el tema central del documento. Por ejemplo, bens (bienes) con 5 ocurrencias en el texto original portugués y su traducción francesa, vincula este texto al discurso que trata el tema de la propiedad. Una segunda etapa es cuantificar y calificar las colocaciones, en negritas en la ficha que aparece aquí debajo. 
COLÓN RODRÍGUEZ - La traducción colaborativa activista contemporánea...

\section{Ficha 4}

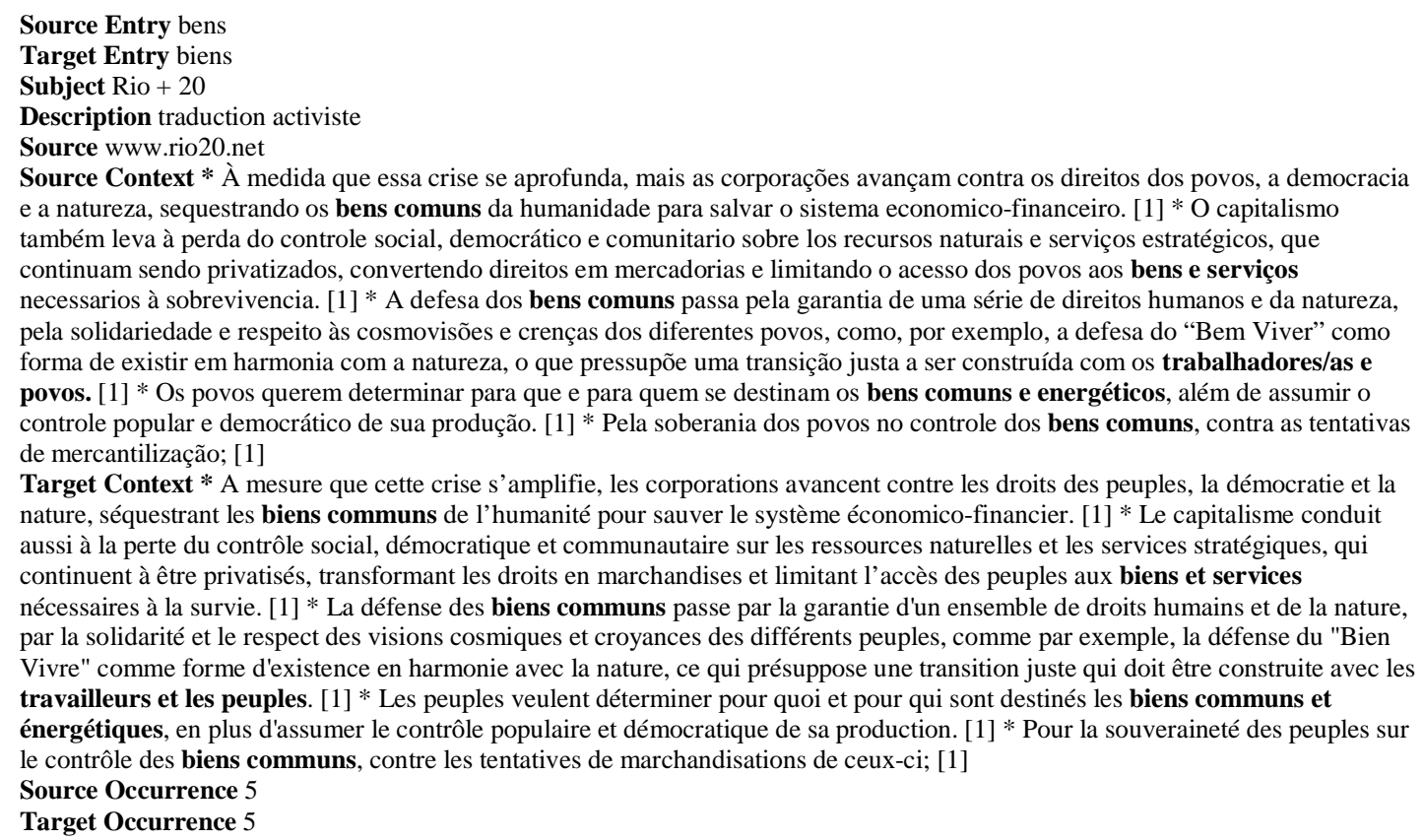

Viendo la recurrencia del término elegido en colocación con el adjetivo communs, (bienes comunes), se puede establecer que se trata de un discurso anticapitalista y marxisante ${ }^{49}$, en particular en el contexto de una colocación más amplia que no muestra la ficha, pero que sí aporta una lectura detenida del texto, con términos clave tales como: corporations, capitalisme, système économico-financier, le droit [comme] marchandise, etc. Es necesario precisar que siguiendo el contexto aportado por SynchroTerm, se puede determinar también que además de este discurso anticapitalista y marxisante están presentes otros, que podríamos calificar de secundarios o colaterales. Ellos aparecen con los términos-ideologemas: droits des peuples, la démocratie et la nature, contrôle social, démocratique et communautaire, l'accès des peuples, respect des visions cosmiques et croyances des différents peuples. Todos esos términos nos remiten a discursos

\footnotetext{
${ }^{49}$ Bajo la denominación discurso marxisante, se engloban aquí todos los discursos de la izquierda que evidencian una filiación política marxista, independientemente de una filiación filosófica más o menos coherente con los postulados de Marx y de Engels. El portal lexical del CNRTL francés, califica "marxisant" como sigue: «Relatif au marxisme; qui concerne le marxisme [...]. Conception, démocratie, doctrine, matérialisme, socialisme, vocabulaire marxiste » (Relativo al marxismo; que concierne al marxismo [...]. Concepción, democracia, doctrina, materialismo, socialismo, vocabulario marxista). Ver: <http://www.cnrtl.fr/definition/marxisant>. (Página consultada el 14 de febrero del 2013).
} 
COLÓN RODRÍGUEZ - La traducción colaborativa activista contemporánea...

altermundialistas, ecologistas y populistas, de defensa de los derechos de las comunidades autóctonas de las Américas, etc.

En la misma ficha 4, una frase comporta un interés particular, siendo evidencia de un cierto matrimonio entre el discurso marxisante y el populista, que es un discurso que ha ganado espacios en América latina en los últimos años. En el segmento de la traducción: "une transition juste qui doit être construite avec les travailleurs et les peuples", se detecta el cliché ideológico ${ }^{50}$ de travailleurs (los trabajadores, o el proletariado) de las teorías marxistas, de conjunto con aquel propio al discurso populista: les peuples (los pueblos). Este último término-ideologema, desde un punto de vista lógico, debería englobar al precedente $^{51}$, pero la reiteración se debe aquí a la necesidad de conciliación de dos corrientes ideológicas subyacentes. Otra particularidad que se puede ver en esa ficha, esta vez de orden netamente traductivo, es que la utilización del término-ideologema trabalhadores/as en el original portugués, es respetuoso de la cuestión de género propia al discurso feminista. La traducción francesa introduce una connotación diferente al término traducido, porque pierde el vínculo con ese discurso feminista y mantiene sólo el del discurso marxisante. Veremos sin embargo, que en la próxima ficha (5), ese mismo término-ideologema será traducido de una manera más cercana al sentido original, quizás porque el contexto enumerativo de la frase lo permite sin riesgo de otras interpretaciones, aunque invirtiendo los términos y para un contexto puramente francés pueda ser interpretado como relativo a uno de los partidos trotskistas de ese país ${ }^{52}$.

\footnotetext{
${ }^{50}$ Este término-ideologema (cliché ideológico), es utilizado aquí sin connotación peyorativa, sino más bien para nombrar un fenómeno lingüístico de larga tradición. El término posee amplia circulación académica, mucho más importante en francés que en inglés. (Búsqueda realizada en Google el 12 de febrero de 2013)

${ }^{51}$ El diccionario Larousse en línea nos dice: "Ensemble de personnes vivant en société sur un même territoire et unies par des liens culturels, des institutions politiques..." (Conjunto de personas que viven en sociedad, en un mismo territorio y que están unidas por lazos culturales e instituciones políticas). (Página consultada el 12 de febrero de 2013).

${ }^{52}$ Es el caso del partido Lutte Ouvrière, dirigido entre 1973 y 2008 por Arlette Laguilliers, quien comenzaba todos sus discursos con la frase: "Travailleuses, travailleurs". Esta expresión se ha convertido, por efecto metonímico y hasta nuestros días, en el "identificador" del partido como tal. URL: 〈www.ina.fr> (Página consultada el 12 de febrero 2013).
} 
COLÓN RODRÍGUEZ - La traducción colaborativa activista contemporánea...

Ficha 5

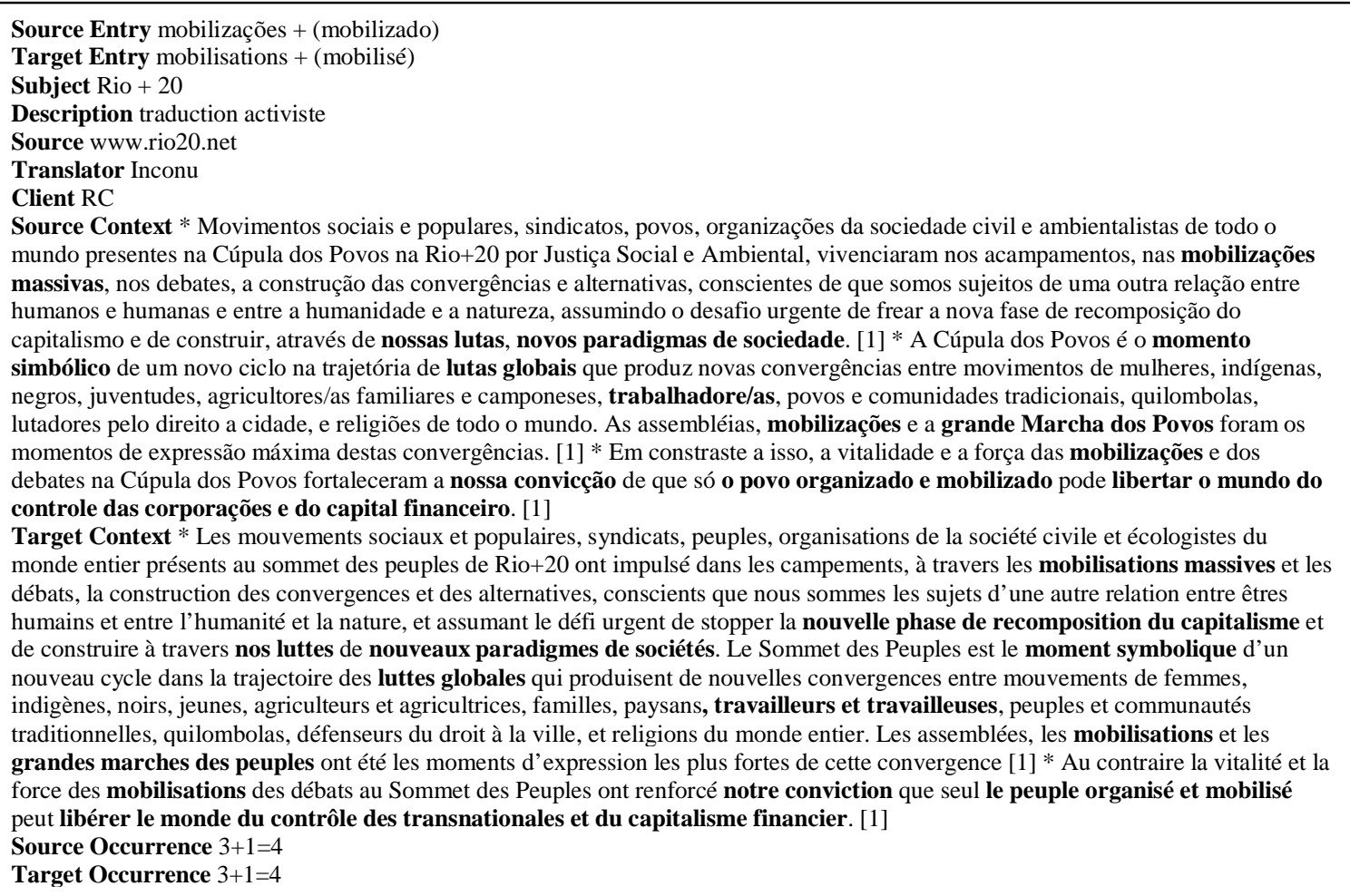

Otro tema central de este documento lo aporta el término-ideologema mobilisations (mobilizaciones). En su forma verbal mobiliser, (mobilizar) y en casi todas sus acepciones, tiene una connotación "militar, militante, sindical" adjetivo massive (masiva) aquí en la ficha 5, o como adjetivo mobilisé (mobilizado), participa igualmente en la emergencia de un discurso marxisante.

Ese discurso es particularmente visible en el contexto de colocación ampliado que muestra la ficha, con términos-clave como: nouvelle phase de recomposition du capitalisme, nos luttes, nouveaux paradigmes de sociétés, moment symbolique, luttes globales, travailleurs et travailleuses, grandes marches des peuples, notre conviction, le peuple organisé et mobilisé, libérer le monde du contrôle des transnationales et du capitalisme financier. Se puede notar que en ese contexto términos pertenecientes a discursos colaterales están también presentes, casi al mismo nivel que el discurso marxisante: mouvements sociaux et populaires, organisations de la société civile et écologistes, construction des convergences et des alternatives, sujets d'une autre relation

\footnotetext{
${ }^{53}$ Ver: Larousse en línea (Página consultada el 12 de febrero del 2013).
} 
COLÓN RODRÍGUEZ - La traducción colaborativa activista contemporánea...

entre êtres humains, l'humanité et la nature, nouvelles convergences entre mouvements de femmes, indigènes, noirs, jeunes, agriculteurs et agricultrices, familles, paysans, travailleurs et travailleuses, peuples et communautés traditionnelles, quilombolas, défenseurs du droit à la ville, y religions du monde entier. Esos términos, en cambio, participan aquí de una enumeración que posee una más marcada intencionalidad retórica y de inclusión de las diferentes fuerzas políticas participantes en la cumbre, que de expresión concreta de los respectivos puntos de vista.

Como conclusión provisoria del corpus brasileño se puede resumir que es representativo del discurso marxisante, en estrecha relación con los discursos contemporáneos que circulan en los espacios altermundialistas donde la Cumbre de los Pueblos tuvo lugar, que se inspira de los documentos programáticos de las cumbres del Fórum Social Mundial y que promueve una vía de luchas de clase y populares y de resolución enérgica de los conflictos sociales en curso.

$* * *$

II.2 Comparación de las palabras claves de los corpus estudiados con el de la OIT a través de TransSearch

Otro programa de Terminotix que nos permite realizar comparaciones cruzadas es TransSearch, "una base de datos de traducciones, con millones de frases traducidas en francés, inglés y español. Un concordanciero bilingüe y una herramienta de ayuda a la redacción", con cuatro bases de datos disponibles, entre las cuales un corpus de la OIT con alrededor de 32 millones de palabras. ${ }^{54}$

Seleccionamos este programa basándonos en el mismo criterio antes utilizado: las herramientas informáticas de ayuda a la traducción pueden y deben ser herramientas de ayuda al estudio de la traducción. El corpus de la OIT nos pareció pertinente con motivo de ser un organismo internacional estrechamente vinculado a las reivindicaciones del activismo contemporáneo y que por ende debe recoger en sus documentos, de una manera

\footnotetext{
${ }^{54}$ Ver la información que sobre TransSearch ofrece el sitio de Terminotix en: <http://www.tsrali.com/〉. (Página consultada el 12 de febrero del 2013).
} 
bastante equilibrada y representativa, la multiplicidad de discursos políticos de los últimos 70 años. Nuestro propósito fue el de contrastar cuantitativamente la presencia de los discursos en los corpus estudiados con el de la OIT.

Primero, analicemos esta tabla con la cantidad de ocurrencias de las palabras-clave (ideologemas) retenidas para el estudio que antecede y otras igualmente representativas, en los corpus de Translating the printemps érable y Rio +20 .

\begin{tabular}{|c|c|c|c|c|}
\hline \multirow[t]{2}{*}{ Ocurrencias de ideologemas } & \multicolumn{2}{|l|}{ Translating } & \multicolumn{2}{|l|}{ Rio +20} \\
\hline & \begin{tabular}{|l} 
Francés \\
1041 palabras
\end{tabular} & $\begin{array}{l}\text { Inglés } \\
1055 \text { palabras }\end{array}$ & \begin{tabular}{|} 
Portugués \\
1247 palabras
\end{tabular} & $\begin{array}{l}\text { Francés } \\
1387 \text { palabras }\end{array}$ \\
\hline $\begin{array}{l}\text { droits fundamentaux-fundamental } \\
\text { rights }\end{array}$ & 2 & 2 & & \\
\hline bens comuns-biens communs & & & 4 & 4 \\
\hline trabalho-travail & & & 3 & 3 \\
\hline démocratie-democracy & 2 & 2 & & \\
\hline raison-reason & 3 & 2 & & \\
\hline $\begin{array}{l}\text { povos, dos povos-peuples, des } \\
\text { peuples }\end{array}$ & & & 55 & 43 \\
\hline abus de pouvoir-abuse of power & 2 & 2 & & \\
\hline luta, lutas-lutte, luttes, de lutte & & & 5 & 9 \\
\hline mobilizações-mobilisations & & & 3 & 4 \\
\hline Totales & 9 & 8 & 70 & 63 \\
\hline
\end{tabular}

De un total de 1041 palabras en el original francés del corpus de Translating, los cuatro ideologemas aquí presentes tienen 9 ocurrencias, para un $0,86 \%$ de ese total. La traducción inglesa con 1055 palabras y 8 ocurrencias de esos cuatro ideologemas tiene un 0,75\%. En Rio+20, un total de 1247 palabras en el original portugués y 70 ocurrencias de los cinco ideologemas seleccionados, nos da un 5,61\% del total. La traducción francesa con 1387 palabras y 63 ocurrencias de los cinco mismos ideologemas, nos da un $4.54 \%$ del total respectivo. Los porcientos pueden parecer bajos, pero es preciso tener en cuenta que es una muy breve selección y que muchos otros ideologemas están presentes en esos textos, conformando más del $50 \%$ de los términos detectados por SynchroTerm en el caso de 
Translating y aproximadamente el $83 \%$ de los términos en el caso de Rio+20. Ello nos hace pensar que estos resultados son representativos de las tendencias de comportamiento entre original y traducción en estas combinaciones de lenguas y en este tipo de texto en particular, algo que ya habíamos confirmado con otro estudio (Colón Rodríguez, 2014). Es decir, que en ambas combinaciones vemos la traducción aumentar la cantidad de palabras en relación al original. En la combinación francés-inglés observamos sin embargo una ligera disminución de la carga ideológica en la traducción y en la combinación portuguésfrancés, aún cuando la cantidad y difusión de los ideologemas en el texto es mayor, se observa igualmente una ligera disminución de la carga ideológicamente activa en la traducción francesa. Factores de diversa índole deben ser estudiados a la hora de explicar estos fenómenos, pues ellos tienen lugar en circunstancias sumamente complejas, pero esa tendencia nos parece suficientemente importante como para dedicarle una especial atención, ¿estaremos en presencia tan solo de un cambio de la tonalidad de los textos activistas traducidos, o se trata de un cambio más profundo, vinculado tal vez a cambios que tienen lugar en la conciencia personal y social de los actores involucrados?

Por otro lado, al realizar una búsqueda en el corpus de la OIT de las palabras-clave estudiadas previamente y en la combinación de lenguas disponible en TransSearch: (francés-inglés) obtuvimos los siguientes resultados:

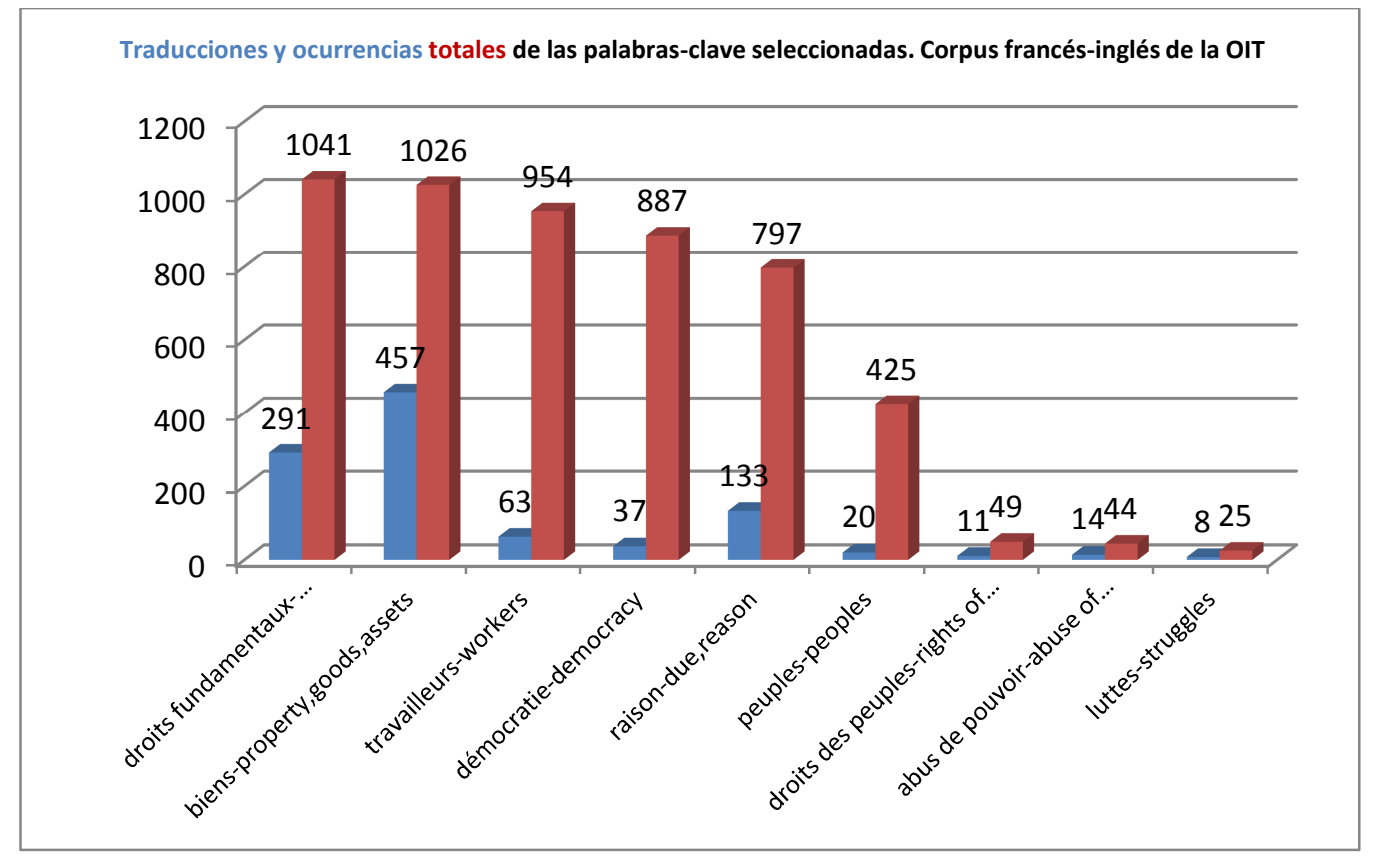


COLÓN RODRÍGUEZ - La traducción colaborativa activista contemporánea...

En un corpus que tiene 45.739.161 palabras, droits fundamentaux (derechos fundamentales) con 1041 ocurrencias, representa un 0,00227\%. Por su parte biens (bienes) con 1026 ocurrencias, representa un $0,00224 \%$, y travailleurs (trabajadores) con 954 ocurrencias, un 0,00208\%. Lo que resulta interesante de estos datos y de esta comparación, es constatar que todos o casi todos los ideologemas que están presentes en los sitios de traducción activista, lo están igualmente en este corpus inmenso, perteneciente a un organismo internacional que sintetiza de manera representativa la terminología activista del siglo $\mathrm{XX}$.

\section{Conclusión}

Maintenant nous avons besoin de ritournelles capables de dès-intriquer chaque souffle singulier du jeu social de la compétition et de la productivité : ritournelles de l'autonomisation psychique et sensitive, ritournelles de singularisation et de sensibilisation (Berardi, p. 8) ${ }^{55}$

Franco Berardi ha clasificado al siglo XX como aquel que "creía en el futuro". Para este autor italiano, el culto de la energía fue la marca de ese tiempo pasado que llegó "a saturar la percepción colectiva y a paralizar la empatía”. Es por eso que aparece esta cita suya encabezando nuestra última reflexión. Los medios alternativos y la traducción colaborativa activista dentro de ellos, contribuye a singularizar el juego social de la competencia y de la productividad, a autonomizarnos psíquica y sensitivamente, a singularizarnos y a sensibilizarnos.

Un nuevo tipo de traducción colaborativa activista parece estar aportando nuevas pistas de desarrollo e investigación de la disciplina pues se dan en los traductores que participan en esos proyectos, características similares a las que se pueden observar en las nuevas profesiones aún no institucionalizadas, las informáticas, por ejemplo, y ello es algo que han resumido con precisión Pérez-González y Susam-Sarajeva:

\footnotetext{
${ }^{55}$ Ahora precisamos de ritornelos capaces de des-intricar cada aliento singular del juego social de la competencia y de la productividad: ritornelos de la autonomización psíquica y sensorial, ritornelos de singularización y de sensibilización.
} 
COLÓN RODRÍGUEZ - La traducción colaborativa activista contemporánea...

They are more prepared to "innovate", play around with the material in hand, retell it in a way that is likely to be more interesting and intelligible for their audience - often because they are themselves part of the audience. $(2012, \text { p. } 158)^{56}$

Translating the printemps érable creó un precedente en la comunidad de traducción activista de Canadá que ya no puede ser ignorado. Rio+20 en Brasil ha operado un movimiento similar, que ya es seguido por otros proyectos sobre la base de una mayor permanencia $^{57}$. La creación y el funcionamiento en formato Web 2.0 que muestran estas experiencias, constituyen no solamente un ejemplo de los nuevos métodos que se desarrollan en el activismo contemporáneo, sino también que esos nuevos métodos reconocen y son portadores de la complejidad de la realidad social en la que están inmersos, una que exige análisis calmados (slow politics) y discusiones mucho más colectivas. Algo que ya Edgar Morin había esbozado cuando escribió:

[...] dans les sociétés complexes comportant pluralismes et antagonismes (sociaux, politiques et culturels), ces antagonismes peuvent s'affronter au sein d'une même esprit, y provoquant conflit intérieur, double bind, crise, recherche. Ainsi, ce qui est présent dans l'esprit individuel n'est pas seulement le Tout comme asservissement, c'est aussi, éventuellement, le Tout comme complexité. (Morin, 2008, p.1652-1653) ${ }^{58}$

Habiendo presentado hace ya casi dos años en el congreso de la ABRAPTFlorianópolis este texto, hoy ya actualizado, inserté en aquella ocasión una cita que vi en un museo de esa ciudad y que me impactara por la pertinencia y actualidad de ese pensamiento. Un oficial federalista brasileño, encargado de restablecer el orden a raíz de la revuelta del Contestado ${ }^{59}$, dijo:

\footnotetext{
${ }^{56}$ Ellos están mejor preparados para "innovar", para manipular el material disponible, para reformular de una manera, que es probablemente más interesante e inteligible para sus auditorios, seguramente por ellos mismos son parte del auditorio.

${ }^{57}$ El portal Rio+20 concluyó cuando la cumbre de Rio del 2012 terminó, pero estamos estudiando en este momento el aporte traductivo que ha hecho el sitio Outras Palavras alrededor del tema de la protesta estudiantil brasileña del 2013. Este sitio trabaja con traductores colaboradores igualmente y pronto tendremos resultados de esos estudios. URL: <http://outraspalavras.net/>.

${ }^{58}$ En las sociedades complejas que comportan pluralismos y antagonismos (sociales, políticos y culturales), esos antagonismos pueden enfrentarse en el seno de un mismo espíritu, provocando conflicto interior, double bind, crisis, búsqueda. De esa manera que lo que está presente en el espíritu individual, no es solamente un Todo de servidumbre, sino también y eventualmente, un Todo de complejidad.

${ }^{59} \mathrm{La}$ "guerra del Contestado" o guerra do Contestado, fue un conflicto armado entre poblaciones mestizas y relativamente independientes y las autoridades brasileñas, entre octubre de 1912 y agosto de 1916. Ese conflicto tuvo lugar en zonas remotas de los estados brasileños de Paraná y de Santa Catarina, así como también en Argentina. Estas zonas "autónomas" eran célebres por sus riquezas y producción de maderas y de yerba mate.
} 
COLÓN RODRÍGUEZ - La traducción colaborativa activista contemporánea...

A revolta do Contestado é apenas uma insurreição de sertanejos espoliados nas suas terras, nos seus direitos e na sua segurança. A questão do Contestado se desfaz com um pouco de instrucão e o suficiente de justiça, como o duplo produto que ela é da violência que revolta e da ignorância que não sabe outro meio de defender o seu direito. Capitão Matos Costa. ${ }^{60}$

Con esta cita de la historia catarinense y brasileira, que muestra lo poco que importa la posición social, o el lado del que se actúa en un conflicto, cuando se tiene un espíritu humanista y una comprensión profunda de la sociedad en que se está operando, quisiera también concluir este texto. Esas palabras me parece adecuadas para evocar el dilema de nuestra contemporaneidad: ¿volveremos a repetir los errores del pasado de uno y de otro lado del poder? ¿Estamos irremediablemente condenados al círculo vicioso: rebeliónopresión-rebelión y de nuevo opresión? Los traductores activistas y los estudiosos de la traducción tenemos en parte la palabra.

Quedan para estudios que seguirán a éste, los análisis de los elementos metafóricos y metonímicos que se observan hoy por hoy en la traducción activista y la colaborativa activista en particular, pues son también estos otros pequeños patrones lingüísticos los que quizás muestran mejor la transición que creemos se está operando, no ya solamente en ámbitos de la traducción y del activismo, sino en general, en las sociedades contemporáneas y a una escala mucho más amplia. Los sucesos en torno a la masacre de Charlie Hebdo han desatado cuestionamientos y han acelerado reacciones que van justamente en el sentido de metaforizar por parte de las fuerzas políticas tradicionales y de metonimizar, por parte de las emergentes. El mundo se hace más complejo y el desafío de la traductología es ayudar, junto con los traductores, a traducirlo.

\section{Bibliografía}

ARENDT, Hannah. Eichmann en Jerusalén. Un estudio sobre la banalidad del mal. Trad.

Carlos Ribalta. Barcelona: Lumen, 2003.

BERARDI, Franco. Média-activisme revisité, (trad. Frédéric Neyrat) Eurozine, 2013.

URL: <http://www.eurozine.com/articles/2013-02-27-berardi-fr.html >

\footnotetext{
${ }^{60}$ La revuelta del Contestado, es apenas una insurrección de campesinos explotados en sus tierras, en sus derechos y en su seguridad. El problema del Contestado se resuelve con un poco de instrucción y la suficiente justicia, como el doble producto que ella es de la violencia que se rebela y de la ignorancia que no conoce otro medio de defender sus derechos. Capitán Matos Costa.
} 
COLÓN RODRÍGUEZ - La traducción colaborativa activista contemporánea...

BLUME, Rosvitha Friesen; PETERLE, Patrícia. Tradução e relações de poder. Florianópolis: PGET-UFSC/Copiart, 2013.

CEIA, Carlos. Ideologema. In: E-Dicionário de Termos Literários (EDTL), 2010. URL: $<$ http://www.edtl.com.pt>

COLÓN RODRÍGUEZ, Raúl Ernesto. Quels rôles civiques pour le traducteur dans le contexte de la globalisation contemporaine?. In: HÉBERT, Lyse (Ed.) Beyond Mediation? Selected Proceedings of the Fourth Graduate Student Conference in Translation Studies, Glendon College, York University, 2014. p. 5-24.

CORMODE, G. y KRISHNAMURTY, B. Key differences between Web 1.0 and Web 2.0. First Monday, vol. 13, n. 6, Jun 2008. URL: <http://firstmonday.org/htbin/cgiwrap/bin/ojs/index.php/fm/article/view/2125/1972> EVEN-ZOHAR, Itamar. Polysystem Theory (revisited). In: EVEN-ZOHAR, Itamar. Papers in Culture Research. Tel Aviv: Porter Chair of Semiotics (Temporary electronic book), 2005.

FLORIDI, Luciano. The $4^{\text {th }}$ Revolution. How the Infosphere is Reshaping Human Reality. Oxford: Oxford University Press, 2014.

GUYON, André. Grandeurs et misères de la traduction collaborative en ligne. L'Actualité langagière, $7(1)$. 2010.

URL:

<www.publications.gc.ca/collections/collection_2010/tpsgc-pwgsc/S52-4-7-1.pdf>

HEATH, Joseph. Enlightenment 2.0. Restoring Sanity to Our Politics, Our Economy, and Our Lives. Toronto: Harper Collins, 2014.

HOUSE, Juliane. Towards a new linguistic-cognitive orientation in translation studies. Target, vol. 25, issue 1, p. 46-60, 2013.

HOBSBAWM, Eric. The Age of Extremes: A History of the World, 1914-1991. New York: Pantheon Books, 1995.

LERUP, Lars. After the City. Cambridge: MIT Press, 2001.

KOZOLANKE, Kirsten et al. Alternative Media in Canada. Vancouver: UBC Press, 2012.

KUHN, Thomas S. The Structure of Scientific Revolutions. Chicago: University of Chicago Press, 1962. 
COLÓN RODRÍGUEZ - La traducción colaborativa activista contemporánea...

L'HOMME, Marie-Claude. La terminologie: principes et techniques. Montréal: Presses de l'Université de Montréal, 2004.

O'HAGAN, Minako (Dir.). Translation as a Social Activity. Comunity Translation 2.0. Linguistica Antverpiensia, n.10, 2011.

O'BRIEN, Sharon. The borrowers. Researching the cognitive aspects of translation. Target, vol. 25, issue 1, p. 5-17, 2013.

MARAIS, Kobus. Translation Theory and Development Studies: A Complexity Approach. New York \& London: Routledge, 2013.

MAYNARD, Andrew. Communication: Science and technology in a connected world. Part 3 of a series on rethinking science and technology for the 21st century, 2009. URL: <http://2020science.org/2009/04/07/communication-science-and-technology-in-aconnected-world/\#ixzz2Zo9TV7gW>.

MILTON, John; EUZEBIO, Eliane. The Political Translations of Monteiro Lobato and Carlos Lacerda. Meta, vol. 49, n. 3, 2004, p. 481-497.

MILTON, John. Tradução: Teoria e Prática, São Paulo: Martins Fontes, 2010.

MORIN, Edgar. Introduction à la pensée complexe. Paris: Seuil, 2005 [1990].

. La Méthode. Paris: Seuil, 2008.

PROJECT PERSEPHONE - Living Architectures. URL : $<$ http://www.icarusinterstellar.org/projects/project-persephone/>

PUNSET, Eduardo. Viaje al poder de la mente. Barcelona: Ediciones Destino, 2010.

ROBINSON, Douglas. What is Translation?: Centrifugal Theories, Critical Intervention. Ashland, USA: Kent State University Press, 1997.

SALDANHA, Gabriela; O'BRIEN, Sharon. Research Methodologies in Translation Studies. Manchester: St.-Jerome, 2013

SLOW POLITICS ANTI-MANIFESTO. In: Slow Politics: International Conference on Power \& Creativity in an Age of Crisis, 2014. URL: <http://www.smal.jp/upload/file/108/slow\%20politics_jp.pdf>

SUSAM-SARAJEVA, Şebnem; PÉREZ-GONZALEZ, Luis. Non-professionals Translating \& Interpreting. Participatory and Engaged Perspectives. The Translator, vol. 8, n.2, 2012. 
COLÓN RODRÍGUEZ - La traducción colaborativa activista contemporánea...

TYULENEV, Sergei. Applying Luhman to Translation Studies: Translation in Society. London: Routledge, 2011.

WILSS, Wolfram. Interdisciplinarity in Translation Studies. Target, vol. 11, issue 1, p. 131-144, 1999. 